\title{
魚肉中のアミンの生成について一II. 魚肉中のヒスタミンの簡易検出法*
}

\author{
太田冬雄 \\ (庵児島大学水産学部)
}

\author{
On the Formation of Amine in Fish Muscle-III. \\ - Simple Method for the Detection of Histamine in Fish Muscle- \\ Fuyuo Ota
}

Simple method for the detection of histamine in fish muscle, based on the extraction of histamine azo-compound with organic solvent, was presented. When $p$-nitroaniline was used for the preparation of diazo-reagent, using ethyl-acetate as a extracting agent, histamine azocompound was easily transfered into the ester and separated from that of histidine. And furthermore the azo-compound of almost all the diazo-reaction positive substances presumably contained in fish muscle was also kept free from being transfered into the ester. At the high concentratation of histidine, histidine azo-compound slightly passed into the ester, but it was possible to remove this by treating with dilute alkaline solution.

Detection procedure was summarized as follows: Fish muscle extract was obtained by shaking and filtering after being added 20 volumes of water (or succesively 10 volumes of water and of $5 \% \mathrm{CCl}_{3} \mathrm{COOH}$ ). To $1.0 \mathrm{cc}$. of the extract, was added $2.0 \mathrm{cc}$. of $2.0 \% \mathrm{Na}_{2} \mathrm{CO}_{3}$. To the above solution, was added $1 \mathrm{cc}$. of diazo-reagent. After brief standing, $7 \mathrm{cc}$. of ethylacetate was added to it and its solution was shaken vigorously. Histamine concentration was measured roughly from the intensity of rose color of ester layer. Diazo-reagent was freshly prepared by adding $0.1 \mathrm{cc}$. of $5 \% \mathrm{NaNO}_{2}$ to $5 \mathrm{cc}$. of $0.1 \% p$-nitroaniline in $0.1 \mathrm{~N} \mathrm{HCl}$ solution, and it was used immediately after preparation.

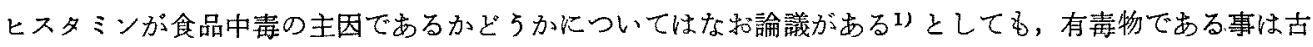

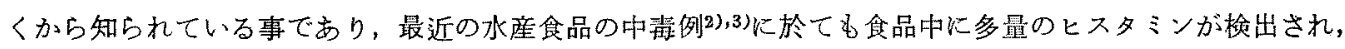
主要な原因物質とされている。しかも一般に鮮度判定指標として利用されている揮発性塩基量は概して少な かつた事が明らがされている。

しかしこの様な事は，元々揮発性塩基とヒスタミンとがその生成機構を異にする事から考克ると当然起り 得る事なのであって，すでに木俣等むは，魚肉の鮮度低下による揮発性塩基とヒスタミンの生成は必らずし る常に平行せず，ある温度 $\left(20^{\circ} \mathrm{C}\right)$ 附近では揮発性䘏基に対しヒスタミンの生成が落しく多く, 従つてこの 様な温度で詝藏された時の揮発性塩基による鮮度判定には危険性のあることを指摘しており，篗者等5 も同 様この事を確かめ，更に広い範囲の温度 $\left(15 \sim 32^{\circ} \mathrm{C}\right)$ に危険性のあることを報告した。

従つてこの様な危険性を防ぐためには，原料の不㒒，加工過程に於ける污染，鮮度の低下を避けるべさは い5までるなく，一方鮮度判定の面からは，従来の鮮度指標の規準量に再检討の必要むむる㥞に思われるが，

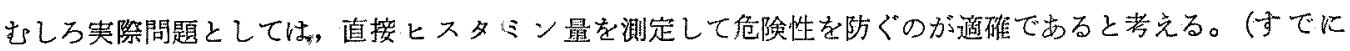
GEIGER ${ }^{6}$ は魚肉の鮮度判定にヒスタミンの測定を提案している)。

しかしそのためには, ヒスタミンの簡易な検出, 定量法が必要なのであるが, 従来の検出, 定量法7 13炏

1957 年 12 月 12 日受理

* 本交の要旨は, 日本水産学会 (1955.4. 東京)にて発表した。 
はこの目的炕適当と思われるものが殆どなく，最近のイオン交換郕炕よる方法14 18)は，これまでの方法に

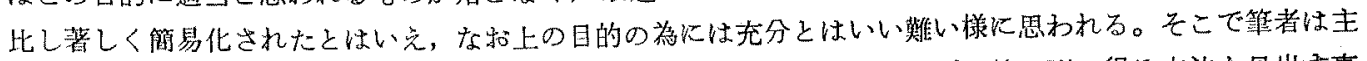

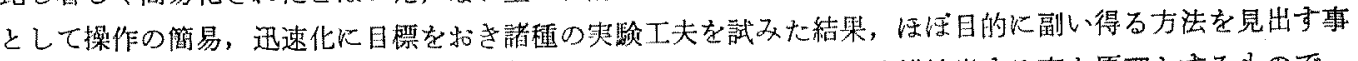
が出来た。方法は要するにヒスタミンのデアゾ呈危物を有機溶剂にて分離抽出する事を原理とするすので， 本文ではこの原理に基くヒスタミンの梌出法について述べる。

\section{実験}

\section{1. 検出操作}

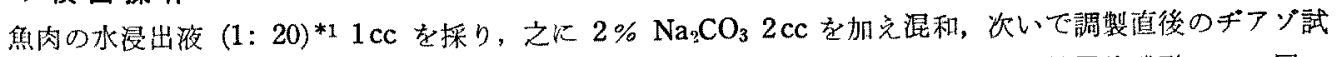

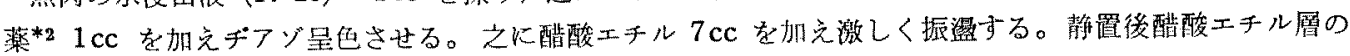

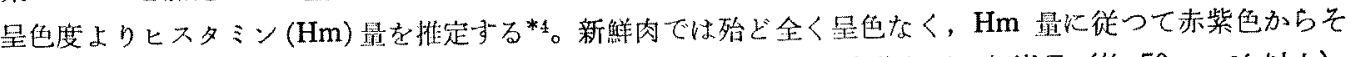

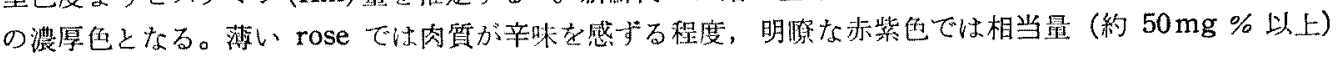
を含むるのと推定される。

\section{2. $\mathrm{Hm}$ 及びヒスチチン (Hd) のアソ色素 $(\mathbf{A Z})$ の有機溶凨への移行性}

本法の原理は，Hm-AZ がある種の有機溶剂飞移行するが，他の AZは移行しない事を前提としている。 そこで先ず，魚肉中のヂアゾ反応陽性物質中，量的に最も多いHd を対象としてその AZ と Hm-AZ との 有㙨溶剂への移行性を比較した。即ち $\mathrm{Hm}$

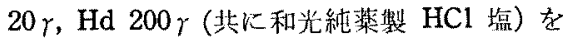
夫々含む溶液他ついて, sulf anilic acid, $p$ nitroaniline 及び $p$-chloroaniline に上る ヂフン゙試薬にて呈色させ，之に大手容易な各 種有幾溶剂加党その移行性を钼察した。そ の結果が Table 1 でる。

移行性はデフゾ試苼調製のための芳香族つ ミン試薬の種類で買なり, sulfanilic acid の

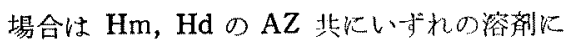
己移行しないが，p-nitroanilinine では極く 限られた溶剂への移行性が見られ，醌酸エス テルに対しては特珙的に Hm-AZ のみが移 行した。又 $p$-chloroaniline では，かなり広 籁な移行性が見られ，エーテル，石油エーテ ル及び $\mathrm{CCl}_{4}$ K刘しては Hm-AZ の灭が移 行し Hd-AZ は殆ど移行しない。之らの結果 からこの方法の基礎条件が㨡めるのである が，実際への適用性の諾点（移行性，水液々 の分離及び回収等の難易）から考充，結局 $p$-nitroaniline によるヂアゾ反応物を醁酸エ チルで抽出するのか゚適当と考克た。即ら $\mathrm{Hm}-\mathrm{AZ}$ は容易に醌酸エチル飞移行し明るい 赤紫色を呈し定性的ではあるが $\mathrm{Hm}$ 滥度に

Table 1. Transferability of the azocompounds of histamine and histidine into organic solvents.

\begin{tabular}{l|c|c|c|c|c|c}
\hline \multirow{2}{*}{\begin{tabular}{l|c|c|c|c|c} 
Organic \\
solvents
\end{tabular}} & \multicolumn{2}{|c|}{$\mathrm{SFA}^{1}$} & \multicolumn{2}{c|}{$\mathrm{PNA}^{2}$} & \multicolumn{2}{c}{$\mathrm{PCA}^{3}$} \\
\cline { 2 - 6 } & $\mathrm{Hm}^{4}$ & $\mathrm{Hd}^{5}$ & $\mathrm{Hm}$ & $\mathrm{Hd}$ & $\mathrm{Hm}$ & $\mathrm{Hd}$ \\
\hline Ether & - & - & - & - & + & \pm \\
Pet. ether & - & - & - & - & + & - \\
Ligroine & - & - & - & - & \pm & - \\
Pet. Benzin & - & - & - & - & \pm & - \\
Chloroform & - & - & - & - & + & \pm \\
Benzene & - & - & - & - & + & \pm \\
CCl & - & - & - & - & + & - \\
CS & - & - & - & - & \pm & - \\
n-Butanol & - & - & + & + & + & + \\
Amyl alcohol & - & - & + & \pm & + & + \\
Toluol & - & - & - & - & + & \pm \\
Xylol & - & - & - & - & + & \pm \\
Methyl acetate & - & - & + & \pm & + & + \\
Ethyl " & - & - & + & - & + & + \\
Butyl " & - & - & + & - & + & + \\
Amyl " & - & - & + & - & + & \pm \\
\hline
\end{tabular}

1 sulfanilic acid, $2 p$-nitroaniline, $3 p$-chloroaniline 4 histamine, 5 histidine.

$+:$ transferable $\pm:$ slightly transferable

- : not transferable 比例し，Hd と共存子る場合飞も同椂儿移行

$*_{1}$ 又俆蛋白沪液。 $*_{2} 0.1 \% p$-nitroaniline の $0.1 \mathrm{~N} \mathrm{HCl}$ 液 $5 \mathrm{cc}$ 飞 $5 \% \mathrm{NaNO}_{2} 0.1 \mathrm{cc}$ を加光る。

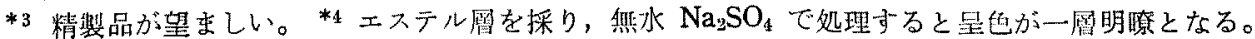


したからである。

\section{3. $\mathrm{Hm}, \mathrm{Hd}$ 以外のチアアソ反応陽性諸物質 $\mathrm{AZ}$ の醋酸エチルへの移行性}

魚肉中には $\mathrm{Hm}, \mathrm{Hd}$ 以外に多くのデフゾ反応陽性物質の存在が知られている。そこで之らの $\mathrm{AZ}$ の醋酸 エチルへの移行性をしらべな。即ち試験磦品の 20〜50万を含む溶液について微察した結果, チロシン, グフ ニン, キサンチン, フデニン, 尿酸, チミン，ピリドキシン，チアミン，イミダゾールブロビオン酸等の $\mathrm{AZ}$ はいずれも全く移行せず, チラミンの $\mathrm{AZ}$ は僅が移行したが, その淟度に対する呈色度は $\mathrm{Hm}$ に比 し遥か炕低く，移行量も甚だ少なく，Hm と等量の時でも殆で無視できる程度であつた。又イミダゾール醋 酸は, 濃度の高い時に僅か移行したが, 影響として認める程ではなかつた。即ち，Hm-AZ の醋酸エチル への移行性は非常に特異的である。

\section{Hm-AZ の醋酸エチルへの移行性に対する魚肉成分の影䇾}

$\mathrm{Hm}-\mathrm{AZ}$ の呈色或いはその移行性に対し，魚肉中の共存成分の影響が考光られるので，この点についてし らベた。その結棸普通に知られているアミ,酸, 有機塩基, 乳酸, グリコーゲン等ではいずれも殆ど全く影 響なく，僅が尿酸、チアミンが，乙かむかなり多量共存する場合に呈色を多少減少させたが，前者は今の

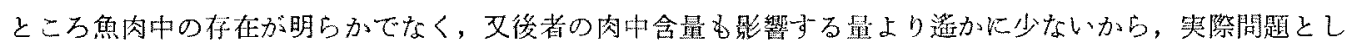

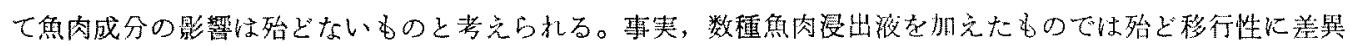
は認められなからた。(之らの諸点については，後報で定量的に亦す。）

\section{5. 醋酸エチルに移行した $\mathrm{Hm}$ 及び Hd の AZ に対する酸, アルカリの影響}

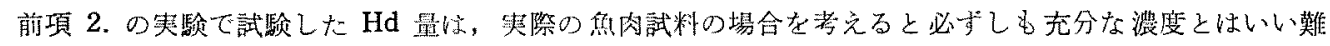
い。そこで更に高浱度（試監渡中 $500 \sim 1000 \gamma$ ) の場合沉ついて試験したところ, Hd-AZ が僅か乍ら移行す

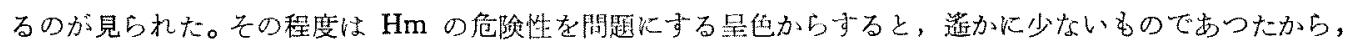
㮥出法としては無視してもよいと思われるが，跤密にはこの影暗を防止することが望ましい。（倦報する定 量法としては当然考えられるべき点である。)

そこで之について若干の工夫の試みたところ，简単な処理で除き得る事が分つた。即ら酷酸エチルに移行 し大微量の $\mathrm{Hd}-\mathrm{AZ}$ は稀 $\mathrm{Na}_{2} \mathrm{CO}_{3}$ で処理与ると容场に $\mathrm{Na}_{2} \mathrm{CO}_{3}$ 層に移行するが， $\mathrm{Hm}$ のそれは全く移行 しない。又稀酸処理では逆に Hm-AZ は酸層に移行するが，Hdのそれは黄変するのみで移行しない。又 中性附近の燐酸緩衝淮では両者共に移行しない。従つて精密な梌出定具のためには当然これらの除去処理 が必要である。

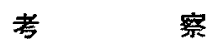

食品中の $\mathrm{Hm}$ 量を求めるからには勿論, 明確な定量値を得ることが望なしい。しかし食品中毒因として

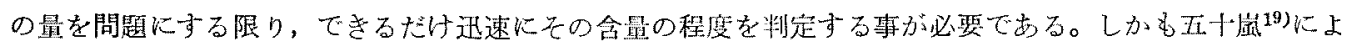

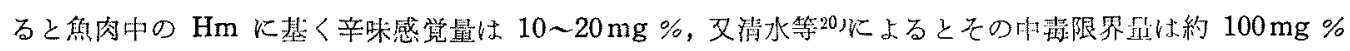

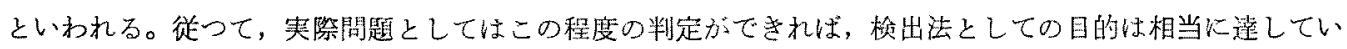
る尼のと考克る。

その点本法は, 所謂检出法としては多少简易さに欠けるか子しれないが，少しく注意すると半定星的な检 出が可能である。即ち本法は叙品衛生上からの Hm 検出法として実用できるるのと考觉る。

要

約

1. 魚肉中のヒスタミン量の簡易に檢出する力法を示した。このう法は $p$-nitroaniline を用いるヂアゾ 反応によるヒスタ、ンアゾ色案を醰酸エチルにて抽出することを原理とする。

2. ヒスタミンアゾ色素は醁酸エチル移行するが，ヒスチヂン及び他のヂフゾ反応陽性物質のアゾ化合 物はいすれも殆ど全く移行しない。ヒスチヂンアゾ色素は高浱度の時に僅かに移行するが，この影響は稀了 ルカリ処理によつて容易炕除かれる。 
3.ヒスタミンアゾ色繠の移行性, 呈色度に対し, 魚肉中の諸成分は殆ど全く影響しない。

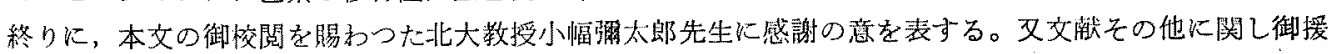

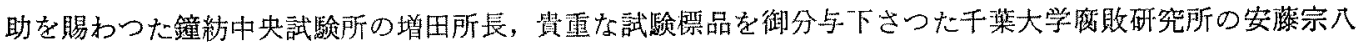
先生及びその御翰旋の学を取つて下ざつた同大学の福山正臣先生亚に本学部黑木助教授に湖せて感謝する。

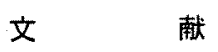

1) 宮木高明: 自然, 7 (12) 12 20, (1952).

2) 柳沢文德：食品衛生，(1957)，p. 41, 共立.

3) 河端俊治 - 石坂公成 -三浦和之：本誌., 21, 335 340, 1167 1170, (1956).

4) 木俣正夫 ·河合 章: 京大食研報告., No. 6, 83 98 (1952).

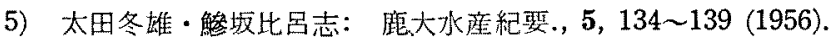

6) E. Geiger: Food Res., 9, 293 297 (1944).

7) K. K. Koessler and M. T. HANke: J. Biol. Chem., 39, 497 (1919).

8) A. H. Eggerth, R. J. Lit rwin and J. V. Deutsch: J. Bact., 37, 187 203 (1939).

9) 秋山義春: 福岡医科., 30, 1 40 (1937).

10) 横山良平: 東京医事新誌., 1948 1953 (1936).

11) 五十嵐登仁：北水誌月報, 1 (1) 24 31 (1944).

12) 門田 元・林孝市郎：京大食研報告., No. 6. 30 35 (1951).

13) 柿本大壳: 鹿大水産紀丝., 3,45 49 (1954).

14) F. C. Mcintire, L. W. Roth and J. L. Shaw: J. Biol. Chem., 170, $537 \sim 544$ (1947).

15) S. M. Rosenthal and H. TABoR: J. Pharmacol. Expte. Teerap., 92, 425 - 431 (1948).

16)門田 元・井上淙太郎: 本誌, 19, 916 920 (1953).

17) R. Lubschez: J. Biol. Chem., 183, $731 \sim 738$ (1950).

18) 小牧瘦夫：日本医学雑誌., 12, 574 587 (1953).

19) 五十㭛应仁：本誌, 8, 161 164 (1939).

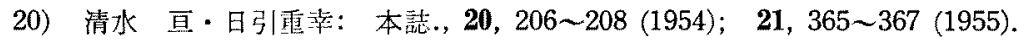

